\title{
The Patient Experience of Gene Therapy for Hemophilia: Qualitative Interviews with Trial Patients
}

This article was published in the following Dove Press journal:

Patient Preference and Adherence

\author{
Wolfgang Miesbach (iD) \\ Robert Klamroth $\mathbb{D}^{2}$ \\ 'Medical Clinic 2, Institute of Transfusion \\ Medicine, University Hospital, Frankfurt, \\ Germany; ${ }^{2}$ Department for Internal \\ Medicine, Vascular Medicine and \\ Coagulation Disorders, Vivantes Klinikum \\ im Friedrichshain, Berlin D - 10249, \\ Germany
}

Background: The phase $1 / 2$ hemophilia B clinical trial (AMT-060) demonstrated stable endogenous FIX levels after 3.5 years (mean FIX activity between 5.1\% and 7.5\%) with continued reductions in annualized bleeds to near zero with the higher dose, and a $78-96 \%$ reduction by year in exogenous FIX use.

Objective: The views of all the three participants from Germany participating in the AMT060 study have been investigated about their experiences with conventional and gene therapy and the effects of the forms of therapy on everyday life.

Patients/Methods: The patients (aged 33-35 years) performed regular prophylactic replacement with factor IX concentrate prior to the gene therapy, reported 0-7 bleeds in the year prior to the treatment, with Hemophilia Joint Health Scores of 0-8. Following topics have been investigated "dealing with illness", "participation in studies", "perception of conventional therapy", "perception of gene therapy", "significance of participation in gene therapy studies", "therapy of haemophilia after the end of the study".

Results: All three participants have started to become more active and do more sports. However, they expressed anxiety about not knowing how long the effect would last and they felt that psychological support would be needed if the factor IX level fell back in the future. No patient expressed concern about any long-term potential negative consequences of gene therapy. Conclusion: Gene therapy has the potential to change the life of patients with haemophilia not only by the reduction of bleeding events but also by the increase of active and sportive activities.

Keywords: gene therapy, haemophilia, patient experience, patient interview

\section{Introduction}

The current standard of care for people with hemophilia (PWH), the replacement of exogenous coagulation factor, has improved significantly in recent decades but remains suboptimal in terms of progressive joint damage, the potential for inhibitor development, poor adherence to therapy and reduced quality of life due to the need for lifelong intravenous injections. ${ }^{1}$

Gene therapy is an attractive therapy strategy for PWH because it eliminates these limitations by providing the potential for stable long-term expression of endogenous coagulation factor activity with one single treatment.

In recent years, Phase 1/2 studies with adeno-associated virus (AAV) vectors have shown that a single administration of AAV vectors can lead to long-term expression of the transgene. ${ }^{2-6}$

Some Phase 3 studies are ongoing to investigate whether the results of Phase 1 studies can be transferred to larger patient populations.
Correspondence: Wolfgang Miesbach Medical Clinic 2, Institute of Transfusion Medicine, University Hospital, Frankfurt, Germany

Tel +4969630I-505I

Email wolfgang.miesbach@kgu.de 
Preliminary data from phase $1 / 2$ hemophilia B clinical trial conducted in the Netherlands, Denmark and Germany (AMT-060) have been published. ${ }^{5}$ This study was based on AAV5 vector with wild-type F9 cDNA in two doses $(5 \times 1012$ to $2 \times 1013 \mathrm{vg} / \mathrm{kg})$.

After 3.5 years of follow-up, there was stable endogenous FIX levels in both cohorts (mean FIX activity between $5.1 \%$ and $7.5 \%$ ) with continued reductions in annualized bleeds to near zero with the higher dose, and a 78-96\% reduction by year in exogenous FIX use. ${ }^{7}$

Apart from case reports, there is no knowledge about the personal experience of patients after gene therapy of haemophilia. ${ }^{8}$ Recently, a multistakeholder group recommended that the transformative nature of gene therapy could be a core part of the outcome measures studied yet an established methodology or instrument to capture this is lacking. ${ }^{9}$ Therefore, we studied the experiences with conventional and gene therapy, the effects of the forms of therapy on everyday life and experiences with participating in the study.

\section{Methods}

In this retrospective case study, guideline-based telephone interviews were conducted with all the three study participants in Germany who had undergone gene therapy as part of the Phase $1 / 2$ study described above ${ }^{5}$ about 3 years ago. These are white male patients with severe hemophilia B aged 33-35 years at the time of receiving gene therapy, with weights ranging from 71 to $89 \mathrm{~kg}$. All three patients performed regular prophylactic replacement with a factor IX concentrate prior to the gene therapy, and reported 0-7 bleeds in the year prior to the treatment, with Hemophilia Joint Health Scores of $0-8 .{ }^{5}$ The interviews were conducted by two independent scientists, audio recorded, verbatim transcribed, pseudonymised and evaluated with thematic analysis in a deductive-inductive procedure. ${ }^{10}$ Clinical data were collected from the patient's files. All data were pseudonymized. Each participant received an unique identification number.

The study was approved by the Ethics Commission of the Goethe University Frankfurt. The patients received patient information and gave their written consent to participate in the study and to process their data. The patient consent included the publication of the case details.

Patient experiences with gene therapy including physical, social and emotional aspects were collected through qualitative, 40-60 mins lasting telephone interviews. The interviews were structured by a pre-defined interview guideline including questions on:

- Gene therapy: conduction, efficacy, satisfaction and challenges, reasons for participating in the trial

- Social aspects such as work, family, friends and social activities

- Physical aspects such as impairments, mobility, daily routine

- Emotional aspects such as fears and concerns, expectations, feeling ill or feeling cured

- Patient care such as preinformation on gene therapy and support

Furthermore, the interviews focused on patients' experienced changes when switching from conventional factor replacement to gene therapy.

To better understand the impact of gene therapy on the daily life of patients with haemophilia, the manuscript was conducted on the basis of a guideline with questions on topics such as "dealing with illness", "participation in studies", "perception of conventional therapy", "perception of gene therapy", "significance of participation in gene therapy studies", "therapy of haemophilia after the end of the study".

\section{Results and Discussion}

All study participants reported that the disease played a greater role in their childhood and adolescence than in adult life. They reported the parents' concern as well as limitations in sports. In adulthood, the disease no longer played a major role in the family. Special restrictions are still experienced in sports due to the avoidance of potential bleeding.

The patients performed regular prophylactic factor substitution at an injection frequency of once weekly to every other day, which was not perceived as very stressful. In fact, the injections had become routine.

As motivation for participating in the gene therapy study, interview partner A reported that he had already participated in studies as a child and was therefore very willing to participate. Interview partner B, who has already participated in several studies, reports similar results. Interview partner $\mathrm{C}$ reports that he was "immediately open to it". The process of information and consent to the participation in the study, however, was very long and complex. 
Although all interviewees perceived conventional therapy in a similar way, they differed in their perception of gene therapy.

Interview partner A quickly became familiar with gene therapy, especially in typical situations where he would have had to substitute coagulation factors with conventional therapy. He feels safer with gene therapy. However, he had initially hoped for a higher factor increase and was now surprised that even the comparatively low factor level was sufficient to make a noticeable difference. In everyday life, it is as if the disease no longer existed.

Interview partner B, on the other hand, found it more difficult to change, to let go of the old injection routine (such familiar with as brushing his teeth) and to trust in the functionality and effectiveness of the gene therapy. He found the breaking with the old injection rhythm, with the routine that he felt was vital, stressful and described the doctors' request to omit the prophylactic injections as difficult. He describes that short after start of the study his upper ankle joint was swollen several times and that in these situations he was worried that this might be due to bleeding. He knew that an increase in the coagulation factor was still detectable. However, this fact alone, unlike interview partner $\mathrm{A}$, did not reassure him or make him fully believe in the effect and functionality of the therapy. For him, the factor values in the blood alone were "too abstract to have this confidence".

In this sense, it had helped him a lot that his attending physician had taken his fears due to the swollen joint seriously and had performed an MRI several times. The many examinations that proved that he was not bleeding into the joint finally calmed him down. He welcomes the fact that frequent injections "no longer have to be in the back of my mind".

Like interview partner $\mathrm{A}$, interview partner $\mathrm{C}$ also feels safer with gene therapy. He describes the elimination of prophylactic injections as an "improvement in the quality of life": Like interview partner A and unlike interview partner B, it is easy for interview partner $\mathrm{C}$ to do without the routine of injecting and trust the new therapy. He is aware of the principle of the gene therapy and trusts the assessment of his treating physician and the measurable factor values in the blood.

The current presence of the disease (after gene therapy) in the interviewees' minds was very different: All study participants reported that a central advantage of gene therapy was that one no longer had to "keep syringes in mind" and that gene therapy "freed up capacities" in him. In addition to the time required for administration, gene therapy also saves time for the procurement and storage of conventional medication.

Interview partner A reported that the disease was no longer present in his everyday thinking. When he thinks of the disease, it is in the context of the controls and his interest in the level of the factor in his blood. Interview partner B also reported that "one no longer thinks about it" except in exceptional situations such as holidays, when the coagulation factor has to be taken along for possible exceptional situations or as part of routine checks.

Everyone has started to become more active and do more sports. Patients started with sporting activities, which they had always been discouraged from doing in the past. One patient started with skating, one patient with karate sports without any traumatic bleedings.

Interview partner $\mathrm{C}$ describes himself as "more willing to take risks" as a result of gene therapy. The participation in the gene therapy study generally gave him a very positive feeling for the future. Gene therapy has made his life "a bit more normal" and gene therapy also gives his underage family members and their parents confidence.

All three study participants feel it as burdening not to know exactly how long the effect would last. However, if the possibility exists, they all would be willing to get treated again with gene therapy, either in studies or after license of this product. One study participant believes that psychological help should be provided in the event of a decline in gene expression: "Because if I am Superman and suddenly no longer have super powers, it's difficult to deal with this alone".

One study participant emphasizes that the prospect of having to bridge the time until a new gene therapy study with syringes is not a problem either, another participant is very confident that he will be able to obtain a form of gene therapy in the future either as part of a follow-up study, a study on another experimental gene therapy method or as a standard medication.

\section{Conclusion}

From these guideline-based telephone interviews can be concluded that gene therapy has the potential to change the life of patients with haemophilia not only by the reduction of bleeding events but also by the increase of active and sportive activities leading to a "normal life", regardless of the genetically underlying bleeding disorders.

\section{Acknowledgments}

We would like to thank Dr. Jennifer Engler and Fabien Engler for their expertise and for conducting the qualified 
interviews and uniQure biopharma B.V. for provision of patient demographic data.

\section{Disclosure}

Prof. Dr. Wolfgang Miesbach reports personal fees, nonfinancial support from uniQure, during the conduct of the study. Dr Robert Klamroth reports personal fees, nonfinancial support from Biomarin, Takeda, Pfizer, and NovoNordisk; grants, personal fees, non-financial support from Bayer and Leo, outside the submitted work. The authors report no other conflicts of interest in this work.

\section{References}

1. Miesbach W, O'Mahony B, Key NS, Makris M. How to discuss gene therapy for haemophilia? A patient and physician perspective. Haemophilia. 2019;25(4):545-557. doi:10.1111/hae.13769

2. Nathwani AC, Tuddenham EG, Rangarajan S, et al. Adenovirusassociated virus vector-mediated gene transfer in hemophilia B. $N$ Engl J Med. 2011;365(25):2357-2365. doi:10.1056/NEJMoa11 08046
3. Nathwani AC, Reiss UM, Tuddenham EG, et al. Long-term safety and efficacy of factor IX gene therapy in hemophilia B. $N$ Engl J Med. 2014;371(21):1994-2004. doi:10.1056/NEJMoa1407309

4. George LA, Sullivan SK, Giermasz A, et al. Hemophilia B gene therapy with a high-specific-activity factor IX variant. $N$ Engl J Med. 2017;377(23):2215-2227. doi:10.1056/NEJMoa1708538

5. Miesbach W, Meijer K, Coppens M, et al. Gene therapy with adeno-associated virus vector 5-human factor IX in adults with hemophilia B. Blood. 2018;131(9):1022-1031. doi:10.1182/blood2017-09-804419

6. Rangarajan S, Walsh L, Lester W, et al. Factor VIII gene transfer in severe hemophilia A. $N$ Engl $J$ Med. 2017;377(26):2519-2530. doi:10.1056/NEJMoa1708483

7. Leebeek F, Meijer K, Coppens M, et al. Stable expression of FIX and maintained reductions in bleeding and factor IX consumption following AMT-060 gene therapy with up to 3.5 years of follow up in adults. Res Pract Thromb Haemost. 2019;3(S1):1-228.

8. Miesbach W, Sawyer E. Practical implications of factor IX gene transfer for individuals with hemophilia B: a clinical perspective. Hum Gene Ther Clin Dev. 2018;29(2):80-89. doi:10.1089/humc. 2017.253

9. Iorio A, Skinner MW, Clearfield E, et al. coreHEM panel. Core outcome set for gene therapy in haemophilia: results of the coreHEM multistakeholder project. Haemophilia. 2018;24(4):e167e172. doi:10.1111/hae.2018.24.issue-4

10. Braun V, Clarke V. Using thematic analysis in psychology. Qual Res Psychol. 2006;3(2):77-101. doi:10.1191/1478088706qp063oa
Patient Preference and Adherence

\section{Publish your work in this journal}

Patient Preference and Adherence is an international, peer-reviewed, open access journal that focuses on the growing importance of patient preference and adherence throughout the therapeutic continuum. Patient satisfaction, acceptability, quality of life, compliance, persistence and their role in developing new therapeutic modalities and compounds to optimize clinical outcomes for existing disease states are major areas of interest for the journal. This journal has been accepted for indexing on PubMed Central. The manuscript management system is completely online and includes a very quick and fair peer-review system, which is all easy to use. Visit http:// www.dovepress.com/testimonials.php to read real quotes from published authors. 